\title{
Violência Doméstica na Agenda da Saúde: Crenças de Gestores de uma Microrregião
}

\section{Domestic Violence in the Health Field: Beliefs of Managers of a Micro-region}

\author{
Lelio Moura Lourenço', Gerson Vieira de Paula Junior²
}

\begin{abstract}
Resumo
O presente estudo buscou identificar crenças de gestores de saúde sobre violência doméstica. Para tanto, foram entrevistados 16 secretários municipais de saúde e 19 coordenadores municipais da Estratégia Saúde da Família de 18 municípios de uma microrregião da Zona da Mata do estado de Minas Gerais, Brasil. O tratamento dos dados foi feito por meio da análise de conteúdo. Os entrevistados apontaram um conjunto de fatores pessoais, familiares e sociais como geradores de violência doméstica. No entanto, as intervenções são pontuais e os resultados assinalam a presença do modelo biomédico permeando o setor de saúde. As dificuldades para intervenção mais ressaltadas foram: vítimas não relatam a violência, pouca participação da comunidade, recurso financeiro insuficiente, pouca articulação intersetorial e ausência de política específica.
\end{abstract}

Palavras-chave: Crenças. Gestão em saúde. Violência doméstica.

\begin{abstract}
The present study sought to identify the beliefs of health managers about domestic violence. To that end, we interviewed 16 municipal health secretaries and 19 municipal coordinators of the Family Health Strategy from 18 municipalities in a micro-region of Zona da Mata, state of Minas Gerais, Brazil. Data processing was made through content analysis. The respondents pointed out a set of personal, family and social factors as domestic violence generators. However, interventions are only done occasionally and the results show the pervasiveness of the biomedical model in the healthcare sector. Respondents highlighted the following challenges as those most often faced by the interventions: victims do not report violence, lack of community participation, insufficient funds, lack of cross-sector articulation and lack of specific policies.
\end{abstract}

Keywords: Beliefs. Health management. Domestic violence.

\footnotetext{
${ }^{1}$ Universidade Federal de Juiz de Fora, Juiz de Fora, Brasil. Contato: leliomlourenco@gmail.com.

${ }^{2}$ Universidade Federal de Juiz de Fora, Juiz de Fora, Brasil. Contato: gersonvpj@hotmail.com.
} 


\section{Introdução}

A violência doméstica pode ser entendida como ações e omissões que prejudicam a saúde, o bem-estar e o desenvolvimento de uma pessoa, praticadas por familiares e/ou outras pessoas que também convivem no espaço doméstico (Brasil, 2002). Apesar de seus impactos negativos, a incorporação do tema da violência na agenda do setor de saúde e a transformação de proposições em intervenções concretas são uma realidade ainda distante (Cavalcanti \& Souza, 2010; Meneghel et al., 2011; Minayo \& Deslandes, 2009; Schraiber et al., 2007). A presente pesquisa aborda as violências praticadas entre membros $\mathrm{da}$ família e entre parceiros íntimos, que podem ser de natureza física, sexual, psicológica e relacionada à privação ou ao abandono (Dahlberg \& Krug, 2002).

A formação e atuação no setor de saúde estão profundamente arraigadas ao modelo biomédico, cultivando no setor uma lógica curativa que dificulta a compreensão e abordagem do fenômeno da violência em sua complexidade (Aragão, Ferriani, Vendruscollo, Souza \& Gomes, 2013; Guedes, Fonseca \& Egry, 2013; Kiss \& Schraiber, 2011; Lima, Rückert, Santos, Colomé \& Acosta, 2009; Oliveira, Almeida \& Morita, 2011; Pedrosa \& Spink, 2011; Signorelli, Auad \& Pereira, 2013). Além disso, de forma geral, a violência é um tema sobre o qual profissionais de saúde têm pouca informação, o que pode ser depreendido pela escassez, apontada por vários estudos, da abordagem desse tema em treinamentos e na formação dos profissionais (Andrade et al., 2011; Aragão et al., 2013; Fonseca, Leal, Skubs, Guedes \& Egry, 2009; Gebara, 2009; Gebara \& Lourenço, 2008; Kiss \& Schraiber, 2011; Lima et al., 2009;
Lourenço, Cruvinel, Almeida \& Gebara, 2010; Oliveira et al., 2011; Sprague et al., 2013; Vieira et al., 2009).

O estudo das crenças de profissionais e gestores de saúde possibilita uma análise psicossocial que considera quem está diretamente envolvido com a proposição e implementação de políticas públicas, podendo contribuir para a compreensão dos processos e dificuldades implicados na inclusão do tema da violência doméstica na agenda do setor de saúde. As pessoas têm inúmeras crenças sobre o mundo social e físico no qual elas vivem e, embora não possam ser observadas diretamente, essas crenças têm consequências comportamentais observáveis e podem ser inferidas a partir do que a pessoa diz ou faz (Rokeach, 1981). Basicamente, crenças são afirmações aceitas por, pelo menos, uma pessoa a respeito de algum objeto ou de alguma relação entre objetos, podendo ser entendidas como opiniões, boatos, dogmas, convicções, conjecturas, estereótipos, entre outras classificações (Krüger, 2006). Assim, se uma pessoa acredita, por exemplo, que o estresse cotidiano e o ritmo de vida atual geram situações de violência doméstica, essa opinião faz parte do sistema de crenças dessa pessoa, podendo essa afirmação corresponder ou não à realidade dos fatos.

Os gestores têm uma participação significativa no que se refere aos rumos do sistema de saúde, já que estão envolvidos com as decisões tomadas e têm sob seu comando os profissionais que prestam cuidados à população. Apesar disso, nos estudos sobre crenças a respeito da violência doméstica, os gestores têm recebido menos atenção do que profissionais de saúde (Paula Junior, Salgado \& Lourenço, 2012). 
Sendo assim, o objetivo deste estudo foi identificar crenças de secretários municipais de saúde e de coordenadores municipais da Estratégia Saúde da Família (ESF) de municípios que pertencem a uma determinada microrregião da Zona da Mata do estado de Minas Gerais, Brasil, a respeito dos fatores geradores de violência doméstica e a respeito do papel do setor de saúde em relação à violência doméstica. Com base nas referências acessadas (Gebara, 2009; Gebara \& Lourenço, 2008; Lourenço et al., 2010) e na experiência dos pesquisadores, foram levantadas as seguintes hipóteses: a) as intervenções do setor de saúde em relação à violência doméstica seriam pontuais e pouco sistematizadas; b) os gestores teriam uma atitude negativa em relação ao pressuposto de que a violência doméstica é um problema que diz respeito também ao setor de saúde; c) os gestores teriam dificuldades para identificar qual seria o papel do setor de saúde em relação à violência doméstica; d) pouca ênfase seria dada à prevenção da violência doméstica no discurso dos gestores.

\section{Método}

\subsection{Participantes}

Nos municípios brasileiros, o sistema de saúde pública é gerido pelo secretário municipal de saúde, cargo de confiança ocupado por alguém escolhido pelo prefeito, que assume a Secretaria Municipal de Saúde, órgão que exerce a direção do Sistema Único de Saúde (SUS) no âmbito da esfera municipal de governo. Entre os diversos setores, programas e projetos do serviço público municipal de saúde encontram-se as equipes da ESF, anteriormente denominada de Programa
Saúde da Família (PSF), formadas por enfermeiro, médico, técnico em enfermagem e agentes comunitários de saúde. Essas equipes se responsabilizam por um território, com determinado número de famílias a serem cuidadas, buscando reorganizar a atenção primária por meio do cuidado integral, contínuo e mais próximo das famílias. Cada município tem um número determinado dessas equipes, de acordo com o tamanho da população.

A presente pesquisa foi realizada em uma microrregião da Zona da Mata do estado de Minas Gerais, Brasil. A escolha do território foi intencional e levou em consideração a facilidade de acesso e de deslocamento dos pesquisadores. A microrregião é composta por 20 municípios. Um deles tem 101.519 habitantes e é considerado polo regional. Os demais são municípios de pequeno porte, com população variando entre 2.192 e 37.972 habitantes. Em quatro municípios (20\% do total), a maior parte da população reside na zona rural. Três municípios apresentam Índice de Desenvolvimento Humano Municipal (IDHM) alto (entre 0,7 e 0,799) e os demais apresentam IDHM médio (entre 0,6 e 0,699).

Os secretários municipais de saúde e os coordenadores municipais da ESF de todos os 20 municípios foram convidados para participarem da pesquisa, totalizando 41 participantes convidados: 20 secretários municipais de saúde e 21 coordenadores municipais da ESF (um dos municípios tem dois coordenadores municipais da ESF). Como alguns se recusaram a participar, o estudo foi realizado em 18 municípios, com a participação de 16 secretários municipais de saúde e 19 coordenadores municipais da ESF. 


\subsection{Instrumento}

Os dados foram coletados por intermédio de entrevista semiestruturada e o roteiro foi elaborado pelos pesquisadores com base em questionário usado em um estudo sobre crenças de agentes comunitários de saúde (Gebara, 2009) e nos objetivos da pesquisa. A primeira parte da entrevista busca caracterizar os participantes do estudo, a segunda se refere às perguntas sobre fatores geradores de violência doméstica e a terceira engloba as perguntas sobre a abordagem da violência doméstica pelo setor de saúde. O roteiro da entrevista é apresentado como apêndice.

\subsection{Procedimentos}

A coleta de dados foi realizada nos anos de 2012 e 2013, em duas etapas. A primeira etapa ocorreu em dois municípios e serviu para testar o roteiro da entrevista, verificar a viabilidade operacional da pesquisa e fazer as modificações necessárias. As análises dos dados obtidos nessa etapa forneceram uma ideia inicial dos possíveis resultados do estudo e um conjunto inicial básico de categorias. Como os procedimentos se desenvolveram conforme planejado, foi dada sequência à coleta de dados nos demais municípios (segunda etapa).

$\mathrm{O}$ pesquisador entrou em contato com os gestores através ligando para os telefones das secretarias municipais de saúde. Após fornecer informações básicas sobre a pesquisa, fez o convite para a participação e agendou as entrevistas com aqueles que aceitaram participar. As entrevistas foram realizadas frente a frente, individualmente, no próprio município onde os participantes trabalhavam. Elas foram gravadas em aparelho digital gravador de voz e transcritas na íntegra para análise.

O tratamento dos dados foi realizado por meio da análise de conteúdo: a partir de sucessivas leituras do material coletado, cada vez mais minuciosas, identificam-se proposições e temas (ou outras unidades de registro) relevantes para o estudo, buscando diferenciá-los em um primeiro momento e depois agrupá-los de acordo com a semelhança de sentido sob uma expressão chave (categoria) que represente o significado central das proposições e temas levantados, procedendose, em seguida, à interpretação do material, baseada na organização dos dados e nas referências ao contexto e aos pressupostos teóricos adotados, citando, ao longo do relatório, recortes das comunicações que fundamentem as conclusões (Amado, 2000), oscilando, assim, entre o rigor da objetividade e a fecundidade da subjetividade (Bardin, 2011). As questões da entrevista foram consideradas como as unidades de contexto. As afirmações dos entrevistados sobre os temas propostos na entrevista foram a unidade de registro utilizada. Essas afirmações foram sintetizadas e agrupadas em categorias temáticas de acordo com o sentido. A presença dessas unidades de registro nas respostas dos participantes foi adotada como indicador. O sistema de categorias não foi fornecido a priori. Ele resultou da análise progressiva do corpo documental.

\subsection{Considerações éticas}

O presente estudo foi aprovado pelo Comitê de Ética em Pesquisa da Universidade Federal de Juiz de Fora, Sendo a aprovação 
efetivada pelo Parecer $\mathrm{n}^{\circ}$ 152.500. Todas as recomendações éticas foram cumpridas, conforme Resolução no 196/96 do Conselho Nacional de Saúde.

\section{Resultados}

A maioria dos secretários municipais de saúde entrevistados é do sexo masculino $(68,8 \%)$, tinham curso superior $(75 \%)$ e formação na área da saúde $(62,5 \%)$. Metade deles tinha mais de um ano de experiência nessa função e a maioria $(87,5 \%)$ não tinha experiência no cargo de coordenador municipal da ESF. Sobre os coordenadores municipais da ESF entrevistados, a maioria é do sexo feminino (78,9\%), tem curso superior completo $(94,7 \%)$, formação na área da saúde $(89,5 \%)$, mais de um ano de experiência nesse cargo $(73,7 \%)$ e não tem experiência no cargo de secretário municipal de saúde (78,9\%).

\subsection{Crenças sobre fatores geradores de violência doméstica}

Os gestores (secretários municipais de saúde e coordenadores municipais da ESF) foram questionados sobre quais fatores eles consideram como os principais geradores de violência doméstica contra crianças, adolescentes, idosos e entre parceiros íntimos. Foram identificados fatores comuns a essas várias situações de violência doméstica e também fatores relacionados especificamente a cada uma dessas situações. Certos fatores foram ressaltados pelos entrevistados em geral, enquanto outros foram enfatizados por algum entrevistado em particular. Por fim, alguns fatores foram mais ressaltados por um dos grupos de gestores do que pelo outro. A descrição a seguir apresenta os resultados agrupados pela combinação dessas cinco possibilidades: a) categorias comuns aos vários tipos de violência doméstica; b) categorias específicas de alguma situação de violência em particular (contra crianças, adolescentes, idosos e entre parceiros íntimos); c) categorias enfatizadas pelos gestores em geral (secretários municipais de saúde e coordenadores municipais da ESF); d) categorias que foram mais ressaltadas por um dos grupos de gestores do que pelo outro grupo; e) categorias enfatizadas por algum participante em particular.

\subsubsection{Categorias comuns aos vários tipos de} violência doméstica

Dentre as categorias comuns, ou seja, que aparecem relacionadas aos vários tipos de violência doméstica, as mais ressaltadas foram: consumo de álcool; consumo de drogas ilícitas; falta de estrutura e de planejamento familiar; falta de diálogo na família; modo e ritmo de vida atual/estresse cotidiano. Além dessas categorias, o grupo de coordenadores municipais da ESF ainda ressaltou fatores socioeconômicos (baixa renda e baixa escolaridade), mas essa categoria não aparece relacionada à violência contra idosos. Ainda em relação aos idosos, a categoria comum mais enfatizada foi o modo e ritmo de vida atual/estresse cotidiano. As demais categorias são citadas, mas não com a mesma ênfase com que aparecem nas outras situações de violência investigadas.

Certos gestores entrevistados enfatizaram alguns fatores que consideram como geradores das várias situações de violência doméstica, mas esses fatores não foram 
enfatizados pelos entrevistados em geral. Em outras palavras, algumas categorias relacionadas aos vários tipos de violência doméstica não foram ressaltadas pelos gestores em geral, mas tiveram destaque nos discursos de algum participante em particular. São elas: herança genética da agressividade; personalidade/ser uma pessoa agressiva; distúrbio mental/agressor não é uma pessoa normal; falta de vivência religiosa; perda dos valores de família; problemas do sistema educacional.

\subsubsection{Violência doméstica contra crianças}

Além das categorias comuns às várias situações de violência doméstica, foram identificadas outras categorias que os gestores estudados relacionaram a um tipo de violência em particular. No caso da violência doméstica contra crianças, as categorias específicas mais ressaltadas foram: cultura geral da violência como uma forma de educar os filhos; pais terem sido criados de forma violenta.

\subsubsection{Violência doméstica contra adolescentes}

Sobre a violência doméstica contra adolescentes, as categorias específicas mais ressaltadas foram: os adolescentes estão sem limites, rebeldes e não querem respeitar os pais; consumo de álcool por parte dos adolescentes; consumo de drogas ilícitas por parte dos adolescentes (segundo os participantes, esses fatores criam uma situação que favorece uma reação agressiva por parte dos pais); os pais não sabem lidar com os filhos adolescentes.

\subsubsection{Violência doméstica contra idosos}

Sobre a violência doméstica contra idosos, destacaram-se as afirmações de que essa situação de violência é gerada quando a família ou outros cuidadores: não têm paciência; não têm informação e nem perfil adequados para cuidar do idoso; estão interessados em ficar com o idoso apenas para usufruir de seus benefícios financeiros. Em certas entrevistas, foram identificadas categorias relacionadas à dificuldade das pessoas e da sociedade em geral para valorizar e se colocar no lugar do idoso: falta de amor, carinho e zelo; pessoas não pensam que serão idosas um dia; sociedade só valoriza as pessoas que são produtivas. $\mathrm{O}$ idoso ter sido agressor no passado foi uma categoria que recebeu destaque no discurso de alguns coordenadores municipais da ESF.

\subsubsection{Violência entre parceiros íntimos}

Sobre a situação de violência entre parceiros íntimos, as categorias específicas mais destacadas em ambos os grupos de gestores foram: ciúmes/insegurança; traição. Os coordenadores municipais da ESF também destacaram a falta de habilidades para lidar com atritos, diferenças e discordâncias como um fator gerador de violência. Além dessas que foram as categorias específicas mais enfatizadas, também receberam destaque em algumas entrevistas: cultura machista patriarcal; crença de ser o dono do parceiro; mulher ama demais e faz qualquer coisa para ficar com o parceiro; vítima não reage e aceita a situação, pois pensa nas qualidades do parceiro ou pensa que ele vai mudar; manutenção de uma relação da qual se arrependeram; vítima 
tem receio/vergonha de se expor; vítima tem medo de reagir.

\subsection{Abordagem da violência doméstica pelo setor de saúde}

Outro tema abordado com os gestores foi a opinião deles sobre qual o papel da saúde pública em relação à violência doméstica. As categorias identificadas foram agrupadas em duas categorias mais amplas: a) prevenção; b) atendimento e gerenciamento dos casos.

Ao todo, 10 secretários municipais de saúde $(62,5 \%)$ mencionaram que é papel do setor da saúde realizar ações de prevenção da violência doméstica, tendo sido identificadas as seguintes ações que deveriam ser desenvolvidas: educação em saúde; atividades para preencher o tempo livre, principalmente dos adolescentes; prevenção ao abuso de álcool e outras drogas; trabalhar a família. Eles também mencionaram atendimento e gerenciamento dos casos de violência doméstica como sendo papel do setor de saúde, tendo sido identificadas as seguintes ações que deveriam ser realizadas: orientar a população para relatar casos de violência doméstica; identificar os casos; notificar; encaminhar a outros setores; orientações às famílias em situação de violência; atendimento/tratamento para as vítimas; atendimento/tratamento do agressor; tratamento para problemas com álcool e drogas ilícitas.

Entre os coordenadores municipais da ESF, oito $(42,10 \%)$ se referiram à prevenção da violência doméstica como sendo papel do setor de saúde, tendo sido identificada a educação em saúde como ação que deveria ser implementada. Em relação ao atendimento e gerenciamento dos casos, foram identificadas as seguintes categorias: orientar as pessoas a relatar/denunciar; identificar os casos; notificar; acolhimento; encaminhar a outros setores; orientações às famílias em situação de violência; atendimento/tratamento para as vítimas; procurar resolver da melhor forma (adotar as condutas consideradas adequadas e possíveis de serem realizadas pela equipe).

No entanto, o discurso dos entrevistados por vezes se mostrou confuso e ambíguo, sugerindo que eles, ou, pelo menos, uma parte deles, não concordam que a violência doméstica é um assunto que diz respeito ao setor de saúde. Os recortes a seguir retratam essas observações.

Na verdade, é o seguinte: a Saúde ela vai, a questão vai, vai vir após a assistente social chegar, dar o parecer que precisa do tratamento psicológico, psiquiátrico de repente, aí cai na questão da Saúde. (7/SMS)

Não. Diz respeito à sociedade também. Né? A sociedade envolve tanto a Saúde, Segurança e principalmente uma Educação. Porque se você tem uma boa educação, você acaba levando essa educação pra vida inteira. Agora, se você não tem, acaba caindo tudo na Saúde ou na parte de Assistência Social. [...] Então eu acho que o negócio é uma questão social. (10/CMESF)

Embora os entrevistados tenham citado ações possíveis de serem realizadas pelo setor de saúde, eles reconhecem que na prática as ações são esporádicas, pontuais e/ou emergenciais e que por vezes o atendimento é prestado por 
profissionais despreparados. Os recortes a seguir referem-se a essas observações.

Eu acho que a Saúde, ela acaba sendo hoje, né, vamos falar assim: o extintor de incêndio pra situação. Certo? Que não seria esse o papel. (4/SMS)

Mas nós trabalhamos como se fôssemos direcionadores, mas a gente não tem mais o que fazer. A gente atende o paciente às vezes violentado, encaminha pra um exame de corpo delito, a pessoa vem tirar a queixa e a gente acompanha enquanto, né, PSF, tá ali acompanhando se tem acontecido, se não tem. E aí? Né? As nossas ações são meramente emergenciais. Né? (12/SMS)

Porque o profissional de saúde, o quê que acontece? Ele não para pra ouvir. Eu chego num consultório médico, eu começo a falar do meu problema, começo a chorar... "Vou passar um diazepam pra você." "Você tá precisando tomar um Rivotril." "Ah, não deu certo não? Então você toma Haldol, Fenergan." Entendeu? Mas ele não parou pra ouvir aquela pessoa. (11/CMESF)

Segundo os participantes, a principal barreira para desenvolver ações relacionadas à violência doméstica é que a pessoa não relata que sofre violência. No entanto, eles reconheceram que esse silêncio tem a ver com uma série de fatores que dificultam esse relato, como $\mathrm{O}$ preconceito por parte da sociedade, vergonha de se expor, não querer prejudicar um parente, receio de o profissional contar para outras pessoas, medo do agressor e a própria dificuldade para falar de um assunto delicado como esse.

As outras dificuldades mais ressaltadas em ambos os grupos de gestores foram agrupadas nas seguintes categorias: comunidade não participa das atividades que são propostas (palestras, por exemplo); recurso financeiro do setor de saúde é insuficiente; pouca articulação intersetorial; ausência de política mais específica que oriente os trabalhos. Além dessas dificuldades, os coordenadores municipais da ESF também destacaram sobrecarga de trabalho dos profissionais de saúde e pequena quantidade de profissionais.

Por fim, alguns entrevistados em particular também destacaram a falta de determinação política como uma das principais dificuldades para desenvolver ações relacionadas ao tema da violência doméstica. Segundo eles, essa barreira se traduz na resposta lenta do estado em relação a esses e a outros problemas, descontinuidade dos projetos, propaganda de projetos que na prática não funcionam como são anunciados, preocupação com votos ou número de eleitores e até no impedimento de implementação de programas no município.

\section{Discussão}

As discussões a seguir foram organizadas em torno de três eixos. Primeiramente, abordamos as diferenças encontradas ao compararmos ambos os grupos de gestores estudados (secretários municipais de saúde e coordenadores municipais da ESF). Em seguida, comparamos as crenças de gestores de saúde (secretários municipais de saúde e coordenadores municipais da ESF), identificadas no presente 
estudo, com as crenças de profissionais de saúde (identificadas em outros estudos). Por fim, procedemos à apresentação da impressão geral apreendida sobre a temática à luz das referências utilizadas.

\subsection{Diferenças entre secretários municipais de saúde e coordenadores municipais da ESF}

De uma forma geral, os resultados em ambos os grupos de gestores estudados foram semelhantes. Porém, há algumas diferenças importantes. Uma delas se refere à crença de que fatores socioeconômicos (baixa renda; pouca escolaridade) são geradores de violência doméstica. Essa categoria foi mais enfatizada pelos coordenadores municipais da ESF do que pelo grupo de secretários municipais de saúde. Os primeiros reconhecem que também há casos de violência doméstica em famílias com melhores condições socioeconômicas, mas consideram que a ocorrência é maior em famílias menos favorecidas socioeconomicamente.

Outra diferença a ser destacada é em relação às dificuldades que o setor de saúde enfrenta para desenvolver ações relacionadas à violência doméstica. As categorias sobrecarga de trabalho dos profissionais de saúde e número insuficiente de profissionais foram mais enfatizadas pelos coordenadores municipais da ESF do que pelo grupo de secretários municipais de saúde.

Essas duas diferenças talvez estejam ligadas ao fato de que, no geral, os coordenadores da ESF não atuam somente na gestão, mas também como profissionais de saúde da ESF. Isso propiciaria: a) um contato cotidiano com a comunidade socioeconomicamente desfavorável que influenciaria essa ênfase nos fatores socioeconômicos; b) vivência da rotina cotidiana dos afazeres de um profissional de saúde, que favoreceria a ênfase na sobrecarga de trabalho e no número reduzido de profissionais. Essas hipóteses, porém, precisam ser investigadas.

Por fim, a crença de que a prevenção da violência doméstica é um dos papéis a serem desempenhados pela saúde pública esteve mais presente nos discursos dos secretários municipais de saúde do que nos discursos dos coordenadores municipais da ESF. Esse resultado chama a atenção porque a proposta da ESF é reorientar o modelo assistencial à saúde em direção ao fortalecimento da Atenção Primária, e o processo de trabalho das equipes nesse nível de cuidados deve ter como características, entre outras, o desenvolvimento de ações com a finalidade de prevenir doenças e danos evitáveis e o desenvolvimento de ações educativas (Brasil, 2012). Assim, esperava-se que a prevenção fosse mais destacada pelo grupo de coordenadores da ESF do que pelo grupo de secretários municipais de saúde.

\subsection{Comparação entre gestores de saúde e profissionais de saúde}

Quando comparamos os resultados do presente estudo, realizado com gestores de saúde (secretários municipais de saúde e coordenadores municipais da ESF), com outros estudos que foram conduzidos com profissionais de saúde, identificamos algumas diferenças importantes. Uma delas se refere às crenças sobre os fatores geradores de violência doméstica. Entre as categorias mais ressaltadas pelos gestores está o modo e ritmo de vida atual/estresse cotidiano. 
Segundo eles, as pessoas têm pouco tempo para a família, chegam a casa cansadas, impacientes e aborrecidas e acabam descontando na família. Essa categoria não foi enfatizada em estudos com profissionais de saúde (Arredondo-Provecho, Pliego-Pilo, Nadal-Rubio \& Roy-Rodríguez, 2008; Gebara, 2009; Gebara \& Lourenço, 2008; Hesler, Costa, Resta \& Colomé, 2013; Kiss \& Schraiber, 2011; Lettiere, Nakano \& Rodrigues, 2008; Lobato, Moraes \& Nascimento, 2012; Lourenço et al., 2010; Moreira, Galvão, Melo \& Azevedo, 2008; Nunes, Sarti \& Ohara, 2008; Paulin Baraldi, Almeida, Perdoná, Vieira \& Santos, 2013; Vieira et al., 2009).

Em relação aos fatores geradores de violência doméstica contra crianças e adolescentes, profissionais de saúde enfatizaram: problemas socioeconômicos; a forma como os pais foram educados (com violência); consumo de álcool e/ou drogas ilícitas; falta de estrutura familiar; aceitação cultural da violência como forma de educar (Gebara, 2009; Gebara \& Lourenço, 2008; Lobato et al., 2012; Lourenço et al., 2010; Nunes et al., 2008). Esses resultados se assemelham às considerações feitas pelos gestores do presente estudo sobre violência contra crianças.

No entanto, em relação à violência contra adolescentes, os gestores do presente estudo consideraram também um conjunto de fatores peculiares que caracterizariam essa situação de violência: consumo de álcool e drogas ilícitas não só pelos pais, mas também pelos adolescentes; rebeldia e falta de limites dos adolescentes; o fato de os pais não saberem lidar com certas características que os gestores consideram próprias da adolescência (ser questionador, questões hormonais). Esse contexto mais específico não foi retratado nos estudos com profissionais de saúde utilizados como referência (Gebara, 2009; Gebara \& Lourenço, 2008; Lobato et al., 2012; Lourenço et al., 2010; Nunes et al., 2008).

Diante disso, cabe destacar que as pesquisas realizadas com os profissionais de saúde que acabamos de citar abordaram a violência contra adolescentes conjuntamente com a violência contra crianças. No presente estudo, optou-se por perguntar sobre essas situações de violência separadamente. Sendo assim, pode ser que os profissionais tenham se concentrado mais na situação da criança ao serem perguntados sobre violência contra crianças e adolescentes conjuntamente. Talvez essa diferença metodológica seja a explicação para os resultados distintos entre profissionais e gestores no que se refere à violência doméstica contra adolescentes.

Entre as dificuldades para desenvolver ações em relação à violência doméstica, os gestores do presente estudo enfatizaram, entre outras, a necessidade de mais recursos financeiros para o setor de saúde. Por outro lado, pouco conhecimento dos profissionais sobre violência doméstica e o medo que os profissionais têm de intervir não foram categorias muito ressaltadas pelos gestores do presente estudo. Esse resultado chama a atenção porque profissionais de saúde consideraram o contrário: eles destacaram a falta de informação sobre o assunto (que não é abordado na formação e nas capacitações), ressaltaram que os profissionais se sentem vulneráveis e têm medo dos agressores e não enfatizaram insuficiência de recursos financeiros do setor de saúde (Aragão et al., 2013; Gebara, 2009; Lima et al., 2009; Lourenço et al., 2010; Signorelli et al., 2013). 


\subsection{Impressão geral do material coletado à luz das referências utilizadas}

De uma maneira geral, os gestores de ambos os grupos abordados no presente estudo (secretários municipais de saúde e coordenadores municipais da ESF) se referiram à violência doméstica como sendo um assunto que diz respeito também ao setor de saúde. No entanto, essa afirmação não foi assim tão clara e enfática em todas as entrevistas. Esse resultado sugere que há gestores que não reconhecem a violência doméstica como objeto de abordagem pelo setor de saúde.

$\mathrm{Na}$ prática, segundo os respondentes, as ações do setor de saúde ainda se concentram na parte curativa, em reação à demanda que chega às unidades de saúde. Muitas vezes, a maneira como os serviços são ofertados e a forma como os profissionais atuam não ajudam a identificar e romper com a situação de violência em que a família se encontra. Por outro lado, é preciso reconhecer que as possibilidades de atuação do setor de saúde são limitadas, o que exige a cooperação de outros seguimentos da sociedade.

De maneira geral, os gestores se mostraram preocupados e sensibilizados com o problema da violência doméstica. As explicações apresentadas para a violência doméstica sugerem que os entrevistados procuram entender $\mathrm{O}$ assunto a partir de uma abordagem multidimensional, pois englobam um conjunto de fatores pessoais, familiares, comunitários, sociais e culturais.

No entanto, há certas limitações e entraves a serem superados: o modelo estritamente biomédico, conhecimento superficial e ações pouco sistematizadas. Foi possível identificar nas mensagens dos gestores a presença de elementos relativos a uma abordagem mais estritamente biomédica no posicionamento de alguns deles, na maneira como o setor está organizado e na forma de atuação de profissionais de saúde. Em alguns discursos, o reconhecimento da violência como um assunto que também diz respeito ao setor de saúde não foi tão claro e enfático. Em geral, as ações de prevenção são esporádicas e a atuação se concentra no atendimento pontual médico e psicológico dos casos que chegam às unidades de saúde. Por vezes, o profissional não procura escutar o usuário de forma mais atenta e acolhedora e a conduta se reduz à prescrição de medicamentos. Além disso, observa-se que algumas respostas foram vagas e imprecisas (por exemplo, "trabalhar a família", "procurar resolver da melhor forma"), sugerindo conhecimento superficial e ações não sistematizadas.

Sendo assim, observa-se no contexto estudado alguma tentativa de entendimento e atuação com base em uma abordagem mais ampliada dos agravos à saúde, mas também a presença de uma abordagem estritamente biomédica no cotidiano dos serviços e até mesmo no discurso de alguns gestores. Essa concomitante presença do modelo biomédico e da busca por uma abordagem alternativa foi observada em estudo realizado com profissionais de saúde e mulheres em situação de violência, revelando atendimentos centrados em preceitos biologizantes, focados em lesões físicas e medicalização, mas também atendimentos centrados na escuta ativa, no estabelecimento de vínculos e em aspectos psicossociais (Signorelli et al., 2013). 
O modelo biomédico aborda o indivíduo em partes, reduz o processo saúde-doença à sua dimensão biológica, defende um distanciamento objetivo entre médico e paciente e propõe uma prática focada na medicalização, coadunando com uma lógica de mercado de uma sociedade que busca um medicamento para quaisquer problemas (Barros, 2002). A formação dos profissionais de saúde encontra-se sob essa abordagem, que se traduz no treinamento centrado na busca de patologias bem definidas (o que não é o caso da violência) e em processos de trabalho centrados na figura do médico (Berger, 2011). Com isso, os profissionais não se sentem à vontade para lidar com dimensões além do nível estritamente biológico, pois para isso não foram preparados (Barros, 2002).

No entanto, não podemos concluir que a influência do modelo biomédico e a falta de abordagem do tema da violência doméstica em cursos e capacitações, inferidas a partir dos resultados e análises do material, embora importante, sejam consideradas como os únicos entraves para a incorporação de fato da violência doméstica na agenda do setor de saúde. Há necessidade de mais estudos com o objetivo de compreender as crenças de gestores e profissionais de saúde e identificar outros fatores que podem promover ou dificultar a proposição e implementação de políticas públicas de saúde referentes à violência doméstica.

\section{Considerações finais}

A abordagem da violência doméstica apresenta-se como um desafio para o setor de saúde, apresentando peculiaridades que expõem as limitações da forma como o sistema de saúde se estrutura na prática e também da formação dos profissionais e gestores de saúde. A situação de violência doméstica requer intervenções diferenciadas e críticas por parte dos profissionais de saúde. Porém, é preciso reconhecer que o setor de saúde não deve atuar sozinho e de forma isolada. É preciso firmar parcerias concretas com outros setores da sociedade para a realização de ações conjuntas e sistemáticas.

Nesse sentido, recomendamos que o tema da violência doméstica receba mais atenção nos cursos de formação, aperfeiçoamento e capacitação de profissionais e gestores de saúde. Também sugerimos que sejam formulados programas e políticas que abarquem de fato a questão da violência e que possam nortear o trabalho dos gestores e profissionais de saúde.

O presente estudo deu voz aos gestores, oferecendo-lhes a possibilidade de se expressarem em relação a um tema sobre o qual eles, juntamente com os profissionais que estão na ponta do sistema, têm sido cada vez mais cobrados. As crenças identificadas podem servir de hipóteses para novos estudos e como temas geradores para subsidiar discussões sobre a temática da violência doméstica. Uma limitação que deve ser problematizada é o fato de que os sujeitos da pesquisa foram abordados ressaltando seu posicionamento gerencial e provavelmente tenderam a falar desse lugar. Assim, a defesa de sua gestão e a reprodução de discursos oficiais podem em algum momento ter se confundido com suas crenças pessoais sobre a temática ou dificultado e inibido a expressão de suas crenças.

Sugerimos a realização de estudos com gestores de regiões com características distintas, de municípios de médio e grande porte (como vimos, a maioria dos municípios incluídos nesse 
estudo são de pequeno porte) e também com gestores de outros segmentos (por exemplo, hospitais). Além disso, novos estudos podem comparar não só grupos de gestores, mas também características intragrupo. Por exemplo, analisar semelhanças e diferenças nas crenças sobre violência doméstica entre gestores do sexo masculino e feminino, entre gestores recémempossados e gestores com mais tempo de experiência, etc.

\section{Referências}

Amado, J. S. (2000). A técnica de análise de conteúdo. Revista de Enfermagem Referência, 1(5), 53-63. Recuperado de http://rr.esenfc.pt/rr/.

Andrade, E. M., Nakamura, E., Paula, C. S., Nascimento, R., Bordin, I. A., \& Martin, D. (2011). A visão dos profissionais de saúde em relação à violência doméstica contra crianças e adolescentes: um estudo qualitativo. Saúde e Sociedade, 20(1), 147-155.

Recuperado de http://dx.doi.org/10.1590/S010412902011000100017.

Aragão, A. de S., Ferriani, M. das G. C., Vendruscollo, T. S., Souza, S. de L., \& Gomes, R. (2013). Abordagem dos casos de violência à criança pela enfermagem na atenção básica. Revista Latino-Americana de Enfermagem, 21(spec.), 172-179.

Recuperado de http://dx.doi.org/10.1590/S010411692013000700022.

Arredondo-Provecho, A. B., del Pliego-Pilo, G., Nadal-Rubio, M., \& Roy-Rodríguez, R. (2008). Knowledge of and opinions on violence against women among health professionals in specialized care. Enfermería Clinica, 18(4), 175-182. Recuperado de http://www.ncbi.nlm.nih.gov/pubmed/1 8724913.

Bardin, L. (2011). Análise de conteúdo (L. A. Reto \& A. Pinheiro, Trad., ed. rev. ampl.). São Paulo: Edições 70.

Barros, J. A. C. (2002). Pensando o processo saúde doença: a que responde o modelo biomédico?. Saúde e Sociedade, 11(1), 67-84. Recuperado de http://dx.doi.org/10.1590/S010412902002000100008.

Berger, S. M. D. (2011). Violência entre parceiros íntimos: desafios no ensino e atenção em saúde. Revista Brasileira de Educação Médica, 35(4), 526-534. Recuperado de http://dx.doi.org/10.1590/S010055022011000400012.

Brasil. Ministério da Saúde. (2002). Violência intrafamiliar: orientações para prática em serviço. Brasília, DF: Secretaria de Políticas de Saúde.

Brasil. Ministério da Saúde. (2012). Politica Nacional de Atenção Básica. Brasília, DF: Secretaria de Atenção à Saúde.

Cavalcanti, M. L. T., \& Souza, E. R. (2010). Percepções de gestores e profissionais de saúde sobre a atenção aos idosos vítimas de violências no município do Rio de Janeiro (RJ, Brasil). Ciência e Saúde Coletiva, 15(6), 2699-2708. Recuperado de http://dx.doi.org/10.1590/S141381232010000600008 .

Dahlberg, L. L., \& Krug, E. G. (2002). Violence: a global public health problem. In E. G. Krug, L. L. Dahlberg, J. A. Mercy, A. B. 
Zwi \& R. Lozano (Orgs.). World report on violence and bealth (pp. 1-21). Geneva, Switzerland: World Health Organization.

Fonseca, R. M. G. S., Leal, A. E. R. B., Skubs, T., Guedes, R. N., \& Egry, E. Y. (2009). Domestic violence against women from the perspective of the community health agent. Revista Latino-Americana de Enfermagem, 17(6), 974-980. Recuperado de http://dx.doi.org/10.1590/S010411692009000600008.

Gebara, C. F. P. (2009). Estudo das crenças dos agentes comunitários de saúde do município de Lima Duarte em relação à violência doméstica contra crianças e adolescentes. Dissertação de mestrado não publicada, Programa de PósGraduação em Psicologia, Universidade Federal de Juiz de Fora, Juiz de Fora, Minas Gerais, Brasil.

Gebara, C. F. P., \& Lourenço, L. M. (2008). Crenças de profissionais da saúde sobre violência doméstica contra crianças e adolescentes. Psicologia em Pesquisa, 2(1), 2739. Recuperado em 30 de maio, 2012, de http://www.ufjf.br/psicologiaempesquisa.

Guedes, R. C., Fonseca, R. M. G. S., \& Egry, E. Y. (2013). Limites e possibilidades avaliativas da estratégia saúde da família para a violência de gênero. Revista da Escola de Enfermagem da USP, 47(2), 304-311. Recuperado de http:/ /dx.doi.org/10.1590/S008062342013000200005.

Hesler, L. Z., da Costa, M. C., Resta, D. G., \& Colomé, I. C. (2013). Violence against women in the perspective of community health agents. Revista Gaúcha de Enfermagem, 34(1), 180-186. Recuperado de
http://dx.doi.org/10.1590/S1983-

14472013000100023.

Kiss, L. B., \& Schraiber, L. B. (2011). Temas médico-sociais e a intervenção em saúde: a violência contra mulheres no discurso dos profissionais. Ciência e Saúde Coletiva, 16(3), 1943-1952. Recuperado de http://dx.doi.org/10.1590/S141381232011000300028.

Krüger, H. (2006). Introdução à Psicologia Social (2a reimp.). São Paulo: EPU.

Lettiere, A., Nakano, A. M. S., \& Rodrigues, D. T. (2008). Violência contra a mulher: a visibilidade do problema para um grupo de profissionais de saúde. Revista da Escola de Enfermagem da USP, 42(3), 467-473. Recuperado de http://dx.doi.org/10.1590/S008062342008000300008.

Lima, M. A. D. S., Rückert, T. R., Santos, J. L. G., Colomé, I. C. S., \& Acosta, A. M. (2009). Atendimento aos usuários em situação de violência: concepções de profissionais de unidades básicas de saúde. Revista Gaúcha e Enfermagem, 30(4), 625-632. Recuperado de http://dx.doi.org/10.1590/S198314472009000400007.

Lobato, G. R., Moraes, C. L., \& Nascimento, M. C. (2012). Desafios da atenção à violência doméstica contra crianças e adolescentes no Programa Saúde da Família em cidade de médio porte do estado do Rio de Janeiro. Cadernos de Saúde Pública, 28(9), 1749-1758.

Recuperado de http:/ /dx.doi.org/10.1590/S0102311 X2012000900013.

Lourenço, L. M., Cruvinel, E., Almeida, A. A., \& Gebara, C. F. P. (2010). Estudo das crenças 
dos agentes de saúde a respeito da violência doméstica. Estudos Interdisciplinares em Psicologia, 1(1), 108-128. Recuperado em 30 maio, 2012, de http://www.uel.br/revistas/uel/index.ph $\mathrm{p} /$ eip.

Meneghel, S. N., Bairros, F., Mueller, B., Monteiro, D., Oliveira, L. P., \& Collaziol, M. E. (2011). Rotas críticas de mulheres em situação de violência: depoimentos de mulheres e operadores em Porto Alegre, Rio Grande do Sul, Brasil. Cadernos de Saúde Pública, 27(4), 743-752. Recuperado de http:/ /dx.doi.org/10.1590/S0102311X2011000400013.

Minayo, M. C. S., \& Deslandes, S. F. (2009). Análise da implantação da rede de atenção às vítimas de acidentes e violências segundo diretrizes da Política Nacional de Redução da Morbimortalidade sobre Violência e Saúde. Ciência \& Saúde Coletiva, 14(5), 1641-1649. Recuperado de http:/ /dx.doi.org/10.1590/S1413-

81232009000500002.

Moreira, S. da N. T., Galvão, L. L. L. F., Melo, C. O. M., \& Azevedo, G. D. (2008). Physical violence against women from the perspective of health professionals. Revista de Saúde Pública, 42(6), 1053-1059. Recuperado de http:/ /dx.doi.org/10.1590/S003489102008005000058.

Nunes, C. B., Sarti, C. A., \& Ohara, C. V. S. (2008). Conceptions held by health professionals on violence against children and adolescents within the family. Revista Latino-Americana de Enfermagem, 16(1), 136141. Recuperado de
http://dx.doi.org/10.1590/S0104-

11692008000100021.

Oliveira, C. C., Almeida, M. A. S., \& Morita, I. (2011). Violência e saúde: concepções de profissionais de uma Unidade Básica de Saúde. Revista Brasileira de Educação Médica, 35(3), 412-420. Recuperado de http:/ /dx.doi.org/10.1590/S010055022011000300016.

Paula Junior, G. V., Salgado, F. S., \& Lourenço, L. M. (2012). A gestão na educação e na saúde concernentes à violência: uma revisão bibliométrica [Resumo]. In Sociedade Brasileira de Psicologia (Org.). Resumos de Comunicação Científica (pp, 2721-2722). XLII Reunião Anual da Sociedade Brasileira de Psicologia e VIII Congresso Iberoamericano de Psicologia. São Paulo: SBP.

Paulin Baraldi, A. C., Almeida, A. M. de, Perdoná, G., Vieira, E. M., \& Santos, M. A. (2013). Perception and attitudes of physicians and nurses about violence against women. Nursing Research and Practice. (Article ID785025). Recuperado de http://dx.doi.org/10.1155/2013/785025.

Pedrosa, C. M., \& Spink, M. J. P. (2011). A violência contra mulher no cotidiano dos serviços de saúde: desafios para a formação médica. Saúde e Sociedade, 20(1), 124-135. Recuperado de http://dx.doi.org/10.1590/S010412902011000100015.

Rokeach, M. (1981). Crenças, atitudes e valores: uma teoria de organização e mudança (A. M. M. Barbosa, Trad.). Rio de Janeiro: Interciência. 
Schraiber, L. B., D’Oliveira, A. F. P. L., Couto, M. T., Hanada, H., Kiss, L. B., Durand, J. G, Puccia, M. I., \& Andrade, M. C. (2007). Violência contra mulheres entre usuárias de serviços públicos de saúde da Grande São Paulo. Revista de Saúde Pública, 41(3), 359-367. Recuperado de http:/ /dx.doi.org/10.1590/S003489102007000300006.

Signorelli, M. C., Auad, D., \& Pereira, P. P. (2013). Violência doméstica contra mulheres e a atuação profissional na atenção primária à saúde: um estudo etnográfico em Matinhos, Paraná, Brasil. Cadernos de Saúde Pública, 29(6), 1230-1240. Recuperado de http:/ dx.doi.org/10.1590/S0102311X2013000600019.

Sprague, S., Kaloty, R., Madden, K., Dosanjh, S., Mathews, D. J., \& Bhandari, M. (2013).
Perceptions of intimate partner violence: a cross sectional survey of surgical residents and medical students. Journal of Injury and Violence Research, 5(1), 1-9. Recuperado de http://dx.doi.org/10.5249/jivr.v5i1.147.

Vieira, E. M., Perdona, G. C. S., Almeida, A. M., Nakano, A. M. S., Santos, M. A., Daltoso, D., \& Ferrante, F. G. (2009). Conhecimentos e atitudes dos profissionais de saúde em relação à violência de gênero. Revista Brasileira de Epidemiologia, 12(4), 566-577. Recuperado de http://dx.doi.org/10.1590/S1415$790 \times 2009000400007$.

Recebido em: 28/3/2018 Aprovado em: 26/6/2018 


\section{Apêndice - Roteiro da Entrevista}

Entrevista $\mathrm{n}^{\circ}$ código Data da entrevista: Contato:

( ) Secretário Municipal de Saúde

( ) Coordenador Municipal da Estratégia Saúde da Família

\section{Introdução}

Muito obrigado por aceitar o convite para participar desta pesquisa com gestores de saúde acerca do tema violência doméstica. Sua participação é muito importante, pois os resultados poderão nos ajudar a compreender melhor o assunto violência doméstica. Por isso, é importante que você dê respostas honestas e completas. Você tem o direito de interromper e se retirar da entrevista a qualquer momento. Esta entrevista será gravada e as informações relatadas serão mantidas em completo anonimato.

\section{Informações sociodemográficas}

Sexo: ( ) masculino () feminino

Idade: Estado civil: Escolaridade:

Tempo de trabalho como profissional de saúde:

Tempo de trabalho como Secretário Municipal de Saúde:

Tempo de trabalho como Coordenador da Estratégia Saúde da Família:

Tempo de trabalho como Secretário Municipal de Saúde deste município:

Tempo de trabalho como Coordenador da Estratégia Saúde da Família deste município:

\section{Questões sobre crenças e violência}

1. Na sua opinião, quais são os principais fatores geradores de violência doméstica/intrafamiliar contra crianças?

2. Na sua opinião, quais são os principais fatores geradores de violência doméstica/intrafamiliar contra adolescentes?

3. Na sua opinião, quais são os principais fatores geradores de violência doméstica/intrafamiliar contra idosos?

4. Na sua opinião, quais os principais fatores geradores de violência entre parceiros íntimos?

5. Na sua opinião, a violência doméstica/intrafamiliar é um assunto que diz respeito ao Setor Saúde? Por quê?

6. Na sua opinião, qual é o papel da Saúde Pública em relação ao tema violência doméstica? 
7. Na sua opinião, quais são as principais dificuldades do Setor Saúde para desenvolver ações relacionadas ao tema violência doméstica/intrafamiliar?

8. Existe algum projeto sobre violência doméstica/intrafamiliar sendo desenvolvido neste município com a participação do Setor Saúde?

Em caso afirmativo:

Fale sobre esse projeto: a) Como começou? b) Como é realizado? c) Quais as dificuldades enfrentadas? d) Quais os principais resultados?

\section{Conclusão da entrevista}

Você gostaria de dizer mais alguma coisa ou fazer mais alguma pergunta?

Muito obrigado pela sua ajuda. Tenha um bom dia e um bom trabalho. 